\title{
Surgical treatment of synchronous multiple primary lung cancers: Experience of 92 patients
}

\author{
Yih-Leong Chang, MD, ${ }^{a}$ Chen-Tu Wu, MD, a and Yung-Chie Lee, MD, $\mathrm{PhD}^{\mathrm{b}}$
}

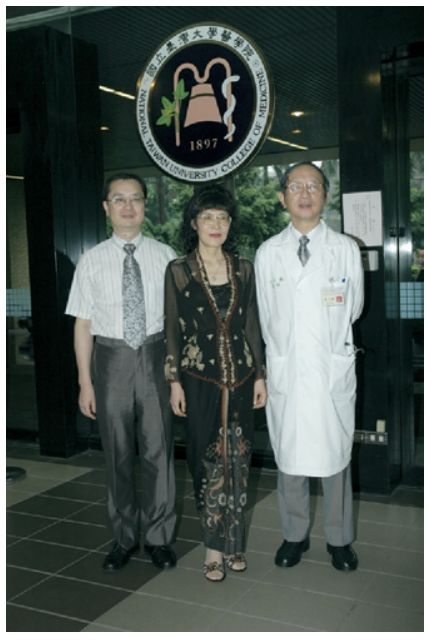

Drs Wu, Chang, and Lee (left to right)
Objectives: According to our previous study, the concurrent detection of p53 and epidermal growth factor receptor mutations significantly improves the clonality assessment and impact management of patients with multiple primary lung cancer. Nevertheless, the treatment, outcome, and safety of patients with this complex disease remain controversial. This series of cases detail our experiences with surgical resections in 92 patients during the past 16 years.

Methods: A database of 1651 patients was evaluated for unilateral and bilateral synchronous multiple primary lung cancers. The relationships among the location of tumors, number of tumors, tumor size, tumor histology, vascular invasion, regional lymph node metastasis, extranodal extension, type of surgery, mortality, and survival were analyzed.

Results: The 5-year survival for all synchronous multiple primary lung cancers was $35.3 \%$. The overall surgical mortality was $1.1 \%$. Notably, lymph node metastasis, extranodal extension, vascular invasion, tumors with adenosquamous carcinoma or different histology, and poor survival were observed. Multivariate analysis showed that only the occurrence of lymph node metastasis remained a statistically significant prognostic factor. The 5-year survivals were $52.5 \%$ and $15.5 \%$ for patients with and without lymph node metastasis, respectively $(P<.001)$.

Conclusion: An aggressive surgical approach is safe and justified in patients with synchronous multiple primary lung cancers and node-negative diseases. The status of this particular form of non-small cell lung cancers might be considered in the conventional TNM staging system for more accurate prediction of patient prognosis.

$\mathrm{T}$ he development of two primary lung cancers was first described by Beyreuther ${ }^{1}$ in 1924, and since then, there have been many reports of multiple primary lung cancers (MPLCs) in the literature. The actual frequency of MPLCs is unknown, but it varies from $0.8 \%$ to $14.5 \%$ depending on whether it was calculated from a cancer registry, autopsy series, or surgical series. ${ }^{2}$ The incidence of synchronous MPLCs in reported clinical series ranges from $1 \%$ to $8 \%{ }^{3}$ The simultaneous discovery of more than 1 pulmonary nodules raises the clinical dilemma of whether these lesions represent multifocal diseases with different clonality or intrapulmonary metastases that migrated from the same origin. MPLCs are potentially curable; however, the prognosis is usually poor if intrapulmonary metastasis occurs. ${ }^{4}$

The criteria proposed by Martini and Melamed ${ }^{5}$ in 1975 are still commonly used for the diagnosis of synchronous MPLCs for patient management. The diagnosis is primarily based on the histologic characteristics of the tumors, such as morphology, location, presence or absence of carcinoma in situ, vascular invasion, metastasis, and other empirical features without biological and molecular basis.

In a previous study, ${ }^{6}$ we showed that a high frequency of somatic mutations in the concurrent detection of p53 and epidermal growth factor receptor resulted in a 


\section{Abbreviations and Acronyms \\ MPLC = multiple primary lung cancer \\ NSCLC $=$ non-small cell lung cancer}

high discrimination rate for tumor clonality of MPLCs. The examination not only allowed clear diagnosis of multifocal lung cancers in the majority of patients despite similarities in histopathologic features but also genetically supported the independent field cancerization theory. Notably, the occurrence of lymph node metastasis was more commonly observed in tumors with the same clonality and was associated with poor 5-year patient survival. However, no cor- relation was found between tumor clonality and patient survival.

Revisions in the International System for the Staging of Lung Cancer, adopted in 1997, assigned the T4 descriptor to separate tumor nodules in the same lobe and the M1 descriptor to tumor nodules in a different lobe. ${ }^{7}$ Consequently, these changes shifted the stage of patients with MPLCs to stage IIIB or stage IV. Because patients with stage IIIB or stage IV non-small cell lung cancers (NSCLCs) are considered to have poor prognoses, they are often treated with chemotherapy or chemoradiation therapy and are not offered surgical resection. Our recent results ${ }^{6}$ showing no statistical association between tumor clonality and patient survival implied that patients with adequate pulmonary and

TABLE 1. Correlations between clinicopathologic features and tumor location in synchronous multiple primary lung cancers

\begin{tabular}{|c|c|c|c|c|c|}
\hline \multirow[b]{2}{*}{ Parameters } & \multirow[b]{2}{*}{ No. of patients* } & \multicolumn{3}{|c|}{ Tumor location } & \multirow[b]{2}{*}{$P$ value } \\
\hline & & One lobe (\%) & $>1$ lobe unilateral $(\%)$ & $>1$ lobe bilateral (\%) & \\
\hline Total patients & 92 & $55(59.8)$ & $26(28.2)$ & $11(12.0)$ & \\
\hline \multicolumn{6}{|l|}{ Sex } \\
\hline Male & 52 & $37(71.2)$ & $10(19.2)$ & $5(9.6)$ & \\
\hline Female & 40 & $18(45.0)$ & $16(40.0)$ & $6(15.0)$ & .037 \\
\hline \multicolumn{6}{|l|}{ Age (y) } \\
\hline$>50$ & 81 & $47(58.0)$ & $24(29.6)$ & $10(12.3)$ & \\
\hline$\leq 50$ & 11 & $8(72.7)$ & $2(18.2)$ & $1(9.1)$ & .642 \\
\hline \multicolumn{6}{|l|}{ Smoking status } \\
\hline Positive & 31 & $24(77.4)$ & $6(19.4)$ & $1(3.2)$ & \\
\hline Negative & 59 & $29(49.2)$ & $20(33.9)$ & $10(16.9)$ & .025 \\
\hline \multicolumn{6}{|l|}{ Type of operation } \\
\hline Lobectomy or pneumonectomy & 82 & $50(61.0)$ & $23(28.0)$ & $9(11.0)$ & \\
\hline Wedge resection or segmentectomy & 10 & $5(50.0)$ & $3(30.0)$ & $2(20.0)$ & .671 \\
\hline \multicolumn{6}{|l|}{ Tumor No. } \\
\hline$<3$ & 38 & $16(42.1)$ & $12(31.6)$ & $10(26.3)$ & \\
\hline$\geq 3$ & 54 & $39(72.2)$ & $14(25.9)$ & $1(1.9)$ & .001 \\
\hline \multicolumn{6}{|l|}{ Largest tumor size $(\mathrm{cm})$} \\
\hline$\leq 3$ & 40 & $27(67.5)$ & $7(17.5)$ & $6(15.0)$ & \\
\hline$>3$ & 51 & $28(54.9)$ & $18(35.3)$ & $5(9.8)$ & .159 \\
\hline \multicolumn{6}{|l|}{ Histologic type } \\
\hline Bronchioloalveolar carcinoma & 4 & $2(50.0)$ & $1(25.0)$ & $1(25.0)$ & \\
\hline Adenocarcinoma & 80 & $49(61.3)$ & $23(28.8)$ & $8(10.0)$ & \\
\hline Squamous cell carcinoma & 3 & $2(66.7)$ & 1 (33.3) & $0(0.0)$ & \\
\hline Adenosquamous carcinoma & 2 & $2(100.0)$ & $0(0.0)$ & $0(0.0)$ & \\
\hline Different subtypes & 3 & $0(0.0)$ & $1(33.3)$ & $2(66.7)$ & .150 \\
\hline \multicolumn{6}{|l|}{ Vascular invasion } \\
\hline Positive & 17 & $10(58.8)$ & $6(35.3)$ & $1(5.9)$ & \\
\hline Negative & 75 & $45(60.0)$ & $20(26.7)$ & $10(13.3)$ & .603 \\
\hline \multicolumn{6}{|l|}{ Lymph node metastasis } \\
\hline Positive & 42 & $28(66.7)$ & $13(31.0)$ & $1(2.4)$ & \\
\hline Negative & 50 & $27(54.0)$ & $13(26.0)$ & $10(20.0)$ & .034 \\
\hline \multicolumn{6}{|l|}{ Extranodal extension } \\
\hline Positive & 17 & $12(70.6)$ & $5(29.4)$ & $0(0.0)$ & \\
\hline Negative & 73 & $41(56.2)$ & $21(28.8)$ & $11(15.1)$ & .218 \\
\hline
\end{tabular}

*Some of the patients lack information. 
physiologic reserve could undergo surgical resection of these lesions. The purpose of this report is to detail our experience with this particular form of NSCLC and to determine the prognostic criteria for selection of patients for aggressive surgical treatment.

\section{Materials and Methods}

\section{Patients and Tumor Specimens}

Ninety-two cases were collected from 1651 patients with primary lung cancer who underwent complete surgical resection at $\mathrm{Na}$ tional Taiwan University Hospital between 1990 and 2006. The study was approved by the research ethics committee of this hospital. These patients were not treated with neoadjuvant chemotherapy or irradiation therapy. Synchronous MPLCs were identi- fied if there was radiographic evidence of a second primary tumor at the time of resection of the first tumor or if the second primary tumor was discovered incidentally during surgery or in the resected specimen. Segmentectomy or wedge resection was performed when the patient's pulmonary reserve was thought to be compromised, but this was infrequently done. Patients undergoing lobectomy included all individuals with simple lobectomies, bilobectomies, or sleeve lobectomies. Pneumonectomy was performed in patients with tumor nodules involving each pulmonary lobe of the lung.

On the basis of the anatomic locations of the MPLCs, 3 subsets of tumor nodules were identified: (1) tumors confined to 1 pulmonary lobe, (2) tumors in more than 1 lobe of the unilateral lung, and (3) tumors in more than 1 lobe of both lungs. All resected speci-

TABLE 2. Correlations between clinicopathologic features and tumor number in synchronous multiple primary lung cancers

\begin{tabular}{|c|c|c|c|c|}
\hline \multirow[b]{2}{*}{ Parameters } & \multirow[b]{2}{*}{ No. of patients* } & \multicolumn{2}{|c|}{ Tumor No. } & \multirow[b]{2}{*}{$P$ value } \\
\hline & & $<3(\%)$ & $\geq 3(\%)$ & \\
\hline Total patients & 92 & $38(41.3)$ & $54(58.7)$ & \\
\hline \multicolumn{5}{|l|}{ Sex } \\
\hline Male & 52 & $22(42.3)$ & $30(57.7)$ & \\
\hline Female & 40 & $16(40.0)$ & $24(60.0)$ & .824 \\
\hline \multicolumn{5}{|l|}{ Age (y) } \\
\hline$>50$ & 81 & $35(43.2)$ & $46(56.8)$ & \\
\hline$\leq 50$ & 11 & $3(27.3)$ & $8(72.7)$ & .314 \\
\hline \multicolumn{5}{|l|}{ Smoking status } \\
\hline Positive & 31 & $13(41.9)$ & $18(58.1)$ & \\
\hline Negative & 59 & $25(42.4)$ & $34(57.6)$ & .968 \\
\hline \multicolumn{5}{|l|}{ Type of operation } \\
\hline Lobectomy or pneumonectomy & 82 & $34(41.5)$ & $48(58.5)$ & \\
\hline Wedge resection or segmentectomy & 10 & $4(40.0)$ & $6(60.0)$ & .929 \\
\hline \multicolumn{5}{|l|}{ Tumor location } \\
\hline 1 lobe & 55 & $16(29.1)$ & $39(70.9)$ & \\
\hline$>1$ lobe, unilateral & 26 & $12(46.2)$ & $14(53.8)$ & \\
\hline$>1$ lobe, bilateral & 11 & $10(90.9)$ & $1(9.1)$ & .001 \\
\hline \multicolumn{5}{|l|}{ Largest tumor size $(\mathrm{cm})$} \\
\hline$\leq 3$ & 40 & $14(35.0)$ & $26(65.0)$ & \\
\hline$>3$ & 51 & $23(45.1)$ & $28(54.9)$ & .330 \\
\hline \multicolumn{5}{|l|}{ Histologic type } \\
\hline Bronchioloalveolar carcinoma & 4 & $3(75.0)$ & $1(25.0)$ & \\
\hline Adenocarcinoma & 80 & $31(38.8)$ & $49(61.3)$ & \\
\hline Squamous cell carcinoma & 3 & $2(66.7)$ & 1 (33.3) & \\
\hline Adenosquamous carcinoma & 2 & $0(0.0)$ & $2(100.0)$ & \\
\hline Different subtypes & 3 & $2(66.7)$ & $1(33.3)$ & .278 \\
\hline \multicolumn{5}{|l|}{ Vascular invasion } \\
\hline Positive & 17 & $3(17.6)$ & $14(82.4)$ & \\
\hline Negative & 75 & $35(46.7)$ & $40(53.3)$ & .028 \\
\hline \multicolumn{5}{|l|}{ Lymph node metastasis } \\
\hline Positive & 42 & $14(33.3)$ & $28(66.7)$ & \\
\hline Negative & 50 & $24(48.0)$ & $26(52.0)$ & .155 \\
\hline \multicolumn{5}{|l|}{ Extranodal extension } \\
\hline Positive & 17 & $5(29.4)$ & $12(70.6)$ & \\
\hline Negative & 73 & $32(43.8)$ & $41(56.2)$ & .276 \\
\hline
\end{tabular}

*Some of the patients lack information. 
mens were formalin-fixed and sectioned for microscopic examination after staining with hematoxylin-eosin. Histologic diagnosis and pathologic features were recorded, including the tumor cell type, vascular invasion, regional lymph node metastasis, and extranodal extension, in which cancer cells invaded beyond the lymph node capsule. The number of tumor nodules and the largest tumor sizes were measured. They were separated into 2 groups according to the number of tumors (ie, $<3$ and $\geq 3$ ) and the largest tumor size (ie, $\leq 3 \mathrm{~cm}$ and $>3 \mathrm{~cm}$ ). Patient numbers for some parameters were less because the information was not available in a few cases.

\section{Follow-up}

Surgical mortality was defined as death occurring within 30 days of surgery or death directly related to the procedure even if it occurred more than 30 days postoperatively.

After surgery, these patients were regularly monitored in the outpatient clinic with chest roentgenography, serum carcinoembryonic antigen measurements, and computed tomography or bone scanning, as needed.

\section{Statistical Analysis}

The correlations between various clinicopathologic parameters and the characteristics of synchronous MPLCs were analyzed with Pearson chi-square tests. Survival curves were estimated using the Kaplan-Meier method. The log-rank test was used to compare survival curves. The following factors were modeled in a univariate fashion: sex (male or female), age ( $\leq 50$ or $>50$ years), smoking status (smokers or nonsmokers), type of surgery (lobectomy or pneumonectomy and wedge resection or segmentectomy), location (tumors in 1 lobe and $>1$ lobe of unilateral or both lungs), number of tumors $(<3$ and $\geq 3)$, tumor size $(\leq 3$ $\mathrm{cm}$ and $>3 \mathrm{~cm}$ ), histologic type (bronchioloalveolar carcinoma, adenocarcinoma, squamous cell carcinoma, adenosquamous carcinoma, and different cell types of the tumors), vascular invasion (presence or absence), lymph node metastasis (presence or absence), and extranodal extension (presence or absence). A multivariate Cox proportional hazards regression model was fit with those variables that demonstrated statistical significance $(P<.050)$ in the univariate models. The Statistical

TABLE 3. Correlations between clinicopathologic features and status of lymph node metastasis in synchronous multiple primary lung cancers

\begin{tabular}{|c|c|c|c|c|}
\hline \multirow[b]{2}{*}{ Parameters } & \multirow[b]{2}{*}{ No. of patients* } & \multicolumn{2}{|c|}{ Lymph node metastasis } & \multirow[b]{2}{*}{$P$ value } \\
\hline & & Positive (\%) & Negative (\%) & \\
\hline Total patients & 92 & $42(45.7)$ & $50(54.3)$ & \\
\hline \multicolumn{5}{|l|}{ Sex } \\
\hline Male & 52 & $25(48.1)$ & $27(51.9)$ & \\
\hline Female & 40 & $17(42.5)$ & $23(57.5)$ & .594 \\
\hline \multicolumn{5}{|l|}{ Age (y) } \\
\hline$>50$ & 81 & $39(48.1)$ & $42(51.9)$ & \\
\hline$\leq 50$ & 11 & $3(27.3)$ & $8(72.7)$ & .192 \\
\hline \multicolumn{5}{|l|}{ Smoking status } \\
\hline Positive & 31 & $15(48.4)$ & $16(51.6)$ & \\
\hline Negative & 59 & $27(45.8)$ & $32(54.2)$ & .813 \\
\hline \multicolumn{5}{|l|}{ Tumor location } \\
\hline 1 lobe & 55 & $28(50.9)$ & $27(49.1)$ & \\
\hline$>1$ lobe, unilateral & 26 & $13(50.0)$ & $13(50.0)$ & \\
\hline$>1$ lobe, bilateral & 11 & $1(9.1)$ & $10(90.9)$ & .034 \\
\hline \multicolumn{5}{|l|}{ Tumor No. } \\
\hline$<3$ & 38 & $14(36.8)$ & $24(63.2)$ & \\
\hline$\geq 3$ & 54 & $28(51.9)$ & $26(48.1)$ & .155 \\
\hline \multicolumn{5}{|l|}{ Largest tumor size $(\mathrm{cm})$} \\
\hline$\leq 3$ & 40 & $13(32.5)$ & $27(67.5)$ & \\
\hline$>3$ & 51 & $28(54.9)$ & $23(45.1)$ & .033 \\
\hline \multicolumn{5}{|l|}{ Histologic type } \\
\hline Bronchioloalveolar carcinoma & 4 & $0(0.0)$ & $4(100.0)$ & \\
\hline Adenocarcinoma & 80 & $39(48.8)$ & $41(51.3)$ & \\
\hline Squamous cell carcinoma & 3 & $1(33.3)$ & $2(66.7)$ & \\
\hline Adenosquamous carcinoma & 2 & $2(100.0)$ & $0(0.0)$ & \\
\hline Different subtypes & 3 & $0(0.0)$ & $3(100.0)$ & .068 \\
\hline \multicolumn{5}{|l|}{ Vascular invasion } \\
\hline Positive & 17 & $12(70.6)$ & $5(29.4)$ & \\
\hline Negative & 75 & $30(40.0)$ & $45(60.0)$ & .022 \\
\hline
\end{tabular}

*Some of the patients lack information. 
Package for the Social Sciences version 10.0 software (SPSS Inc, Chicago, Ill) was used for all analyses.

\section{Results}

\section{Patient Demographics}

Of the 92 patients studied, 52 were male and 40 were female. Their ages ranged from 37 to 83 years, with a mean of 64 years. The majority of the patients were nonsmokers $(59 / 90,65.6 \%)$, whereas the majority of the smokers were men $(29 / 31,93.5 \%)$.

\section{Location of Tumors}

Fifty-five patients had multiple lesions in a single lobe $(59.8 \%)$ with a higher propensity for the left upper lobe $(16 / 92,17.4 \%)$, whereas $28.2 \%(26 / 92)$ had lesions in a separate lobe of unilateral and $12.0 \%$ (11/92) had lesions in both lungs. Single lobe lesions were significantly more common among men $(37 / 52,71.2 \%)$ than women $(18 / 40$, $45.0 \%, P=.037)$ and among smokers $(24 / 31,77.4 \%)$ than nonsmokers $(29 / 59,49.2 \%, P=.025$, Table 1$)$.

\section{Number and Size of Tumors}

The number of patients with 3 or more tumors predominated $(54 / 92,58.7 \%)$, whereas $41.3 \%$ of patients had fewer than 3 tumors. Among patients with 3 or more tumors, the tumors were predominantly located in 1 lung lobe $(39 / 55,70.9 \%, P$ $=.001)$, and tumors with vascular invasion were more frequently observed $(14 / 17,82.4 \%, P=.028$, Table 2$)$. Tumor sizes ranged from 0.9 to $10.5 \mathrm{~cm}$ (mean $3.9 \mathrm{~cm}$ ), with $56 \%$ of tumors (51/91) larger than $3 \mathrm{~cm}$ and $44 \%$ of lesions (40/91) $3 \mathrm{~cm}$ or smaller.

\section{Surgical Treatment}

Lobectomy was the procedure most commonly performed (53 patients) in patients who had multiple tumors in the same lobe. Lobectomy was combined with wedge resection in 14 patients in whom the tumors were located in different lobes, either unilaterally or bilaterally; sleeve resection was performed in 1 patient; bilobectomy was performed in 8 patients; and pneumonectomy was performed in 6 patients. Eight patients with small lesions $(\leq 2 \mathrm{~cm})$ in different lobes of unilateral or bilateral lungs underwent multiple wedge resections, 1 patient underwent segmentectomy, and 1 patient underwent segmentectomy plus wedge resection. There was 1 perioperative death in the pneumonectomy group.

\section{Tumor Histologic Analysis}

Eighty-nine patients had 2 or more tumors with the same histologic results. Adenocarcinoma was the predominant histologic type in patients with synchronous MPLCs, occurring in 80 of 92 patients $(87.0 \%)$; other types were bronchioloalveolar carcinomas in 4 patients $(4.3 \%)$, squamous cell carcinomas in 3 patients $(3.3 \%)$, and adenosquamous carcinomas in 2 patients $(2.2 \%)$ (Table 1$)$.
Among the remaining 3 patients, 1 patient had 1 adenosquamous carcinoma and 1 adenocarcinoma, 1 patient had 1 mucinous adenocarcinoma and 1 bronchioloalveolar carcinoma, and 1 patient had 1 adenocarcinoma and 1 bronchioloalveolar carcinoma.

\section{Lymph Node Metastasis}

Lymph node metastasis was significantly more common in patients with tumors greater than $3 \mathrm{~cm}$ in size $(54.9 \%, P=$

TABLE 4. Correlations between clinicopathologic features and survival in patients with synchronous multiple primary lung cancers

\begin{tabular}{|c|c|c|c|}
\hline Variables & $\begin{array}{c}\text { No. of } \\
\text { patients* }\end{array}$ & $\begin{array}{c}\text { No. of } \\
\text { deaths }(\%)\end{array}$ & $\begin{array}{c}P \\
\text { value }\end{array}$ \\
\hline Total patients & 92 & $58(63.0)$ & \\
\hline \multicolumn{4}{|l|}{ Sex } \\
\hline Male & 52 & $37(71.2)$ & \\
\hline Female & 40 & $21(52.5)$ & .102 \\
\hline \multicolumn{4}{|l|}{ Age (y) } \\
\hline$>50$ & 81 & $52(64.2)$ & \\
\hline$\leq 50$ & 11 & $6(54.5)$ & .500 \\
\hline \multicolumn{4}{|l|}{ Smoking status } \\
\hline Positive & 31 & $23(74.2)$ & \\
\hline Negative & 59 & $33(55.9)$ & .189 \\
\hline \multicolumn{4}{|l|}{ Type of operation } \\
\hline Lobectomy or pneumonectomy & 82 & $52(63.4)$ & \\
\hline $\begin{array}{l}\text { Wedge resection or } \\
\text { segmentectomy }\end{array}$ & 10 & $6(60.0)$ & .985 \\
\hline \multicolumn{4}{|l|}{ Tumor location } \\
\hline 1 lobe & 55 & $38(69.1)$ & \\
\hline$>1$ lobe, unilateral & 26 & $15(96.2)$ & \\
\hline$>1$ lobe, bilateral & 11 & $5(45.5)$ & .770 \\
\hline \multicolumn{4}{|l|}{ Tumor number } \\
\hline$<3$ & 38 & $22(57.9)$ & \\
\hline$\geq 3$ & 54 & $36(66.7)$ & .393 \\
\hline \multicolumn{4}{|l|}{ Largest tumor size $(\mathrm{cm})$} \\
\hline$\leq 3$ & 40 & $25(62.5)$ & \\
\hline$>3$ & 51 & $32(62.7)$ & .505 \\
\hline \multicolumn{4}{|l|}{ Histologic type } \\
\hline Bronchioloalveolar carcinoma & 4 & $1(25.0)$ & \\
\hline Adenocarcinoma & 80 & $53(66.3)$ & \\
\hline Squamous cell carcinoma & 3 & $1(33.3)$ & \\
\hline Adenosquamous carcinoma & 2 & $2(100.0)$ & \\
\hline Different subtypes & 3 & $1(33.3)$ & .049 \\
\hline \multicolumn{4}{|l|}{ Vascular invasion } \\
\hline Positive & 17 & $14(82.4)$ & \\
\hline Negative & 75 & $44(58.7)$ & .010 \\
\hline \multicolumn{4}{|l|}{ Lymph node metastasis } \\
\hline Positive & 42 & $35(83.3)$ & \\
\hline Negative & 50 & $23(46.0)$ & $<.001$ \\
\hline \multicolumn{4}{|l|}{ Extranodal extension } \\
\hline Positive & 17 & $15(88.2)$ & \\
\hline Negative & 73 & $41(56.2)$ & .005 \\
\hline
\end{tabular}

*Some of the patients lack information. 


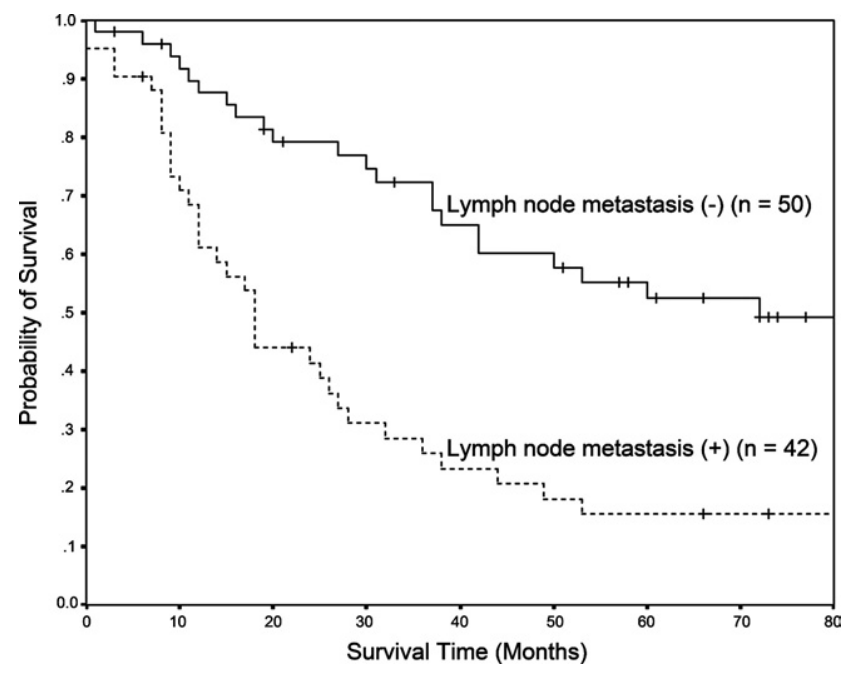

Figure 1. Patients with MPLC with lymph node metastasis tended to have worse survival compared with patients without lymph node metastasis $(P<.001, \log$-rank test). $M P L C$, multiple primary lung cancer.

$.033)$ and those with vascular invasion $(70.6 \%, P=.022)$. Lymph node metastasis occurred less frequently among patients with bilateral MPLCs $(9.1 \%, P=.034)$ (Table 3$)$. Extranodal extension was observed in 17 of 40 patients $(42.5 \%)$ with lymph node metastasis.

\section{Correlations Between Clinicopathologic Features and Survival}

The influence of various clinicopathologic parameters on overall patient survival is shown in Table 4. By using

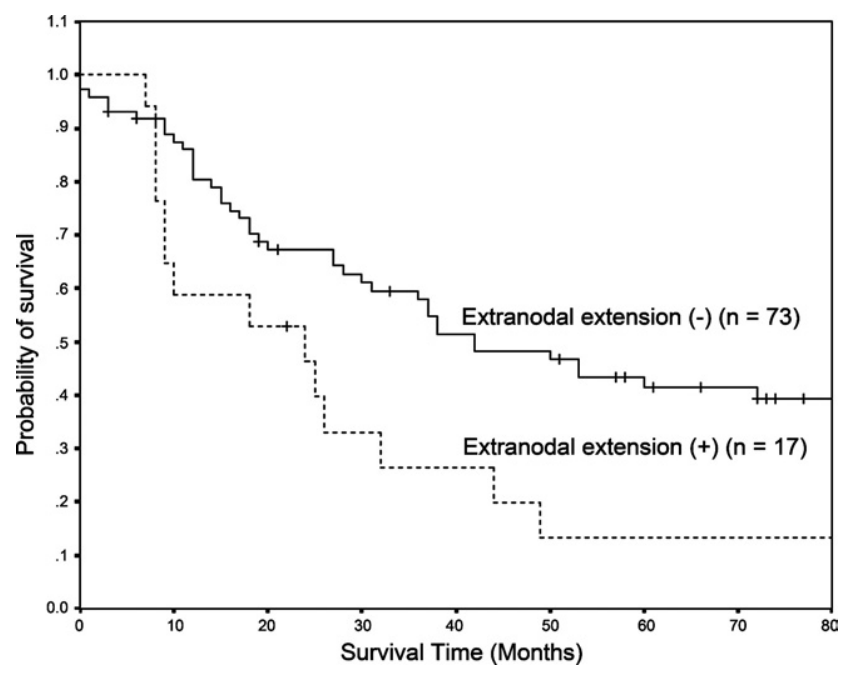

Figure 2. Comparison of survival curves of patients with or without extranodal extension ( $P=.005$, log-rank test).

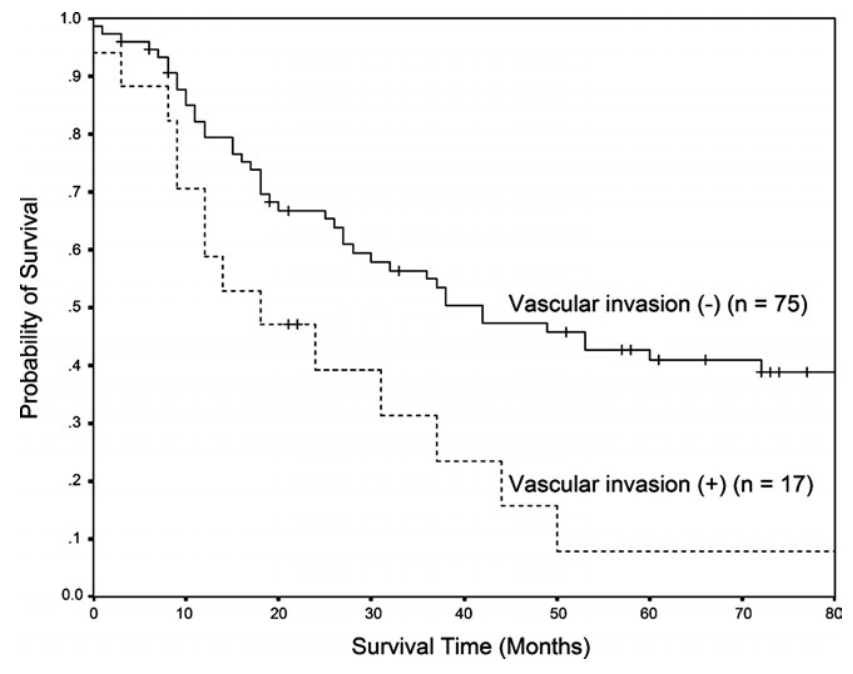

Figure 3. Comparison of survival curves of patients with or without vascular invasion ( $P=.010$, log-rank test).

univariate analysis of survival, the presence of lymph node metastasis (Figure 1), extranodal extension (Figure 2), vascular invasion (Figure 3), and tumors with adenosquamous carcinoma or tumors of different histologic types (Figure 4) were significant adverse prognostic factors. By using multivariate analysis, only the presence of lymph node metastasis remained a statistically significant prognostic factor (Table 5). The 5-year survivals were $52.5 \%$ and $15.5 \%$ for

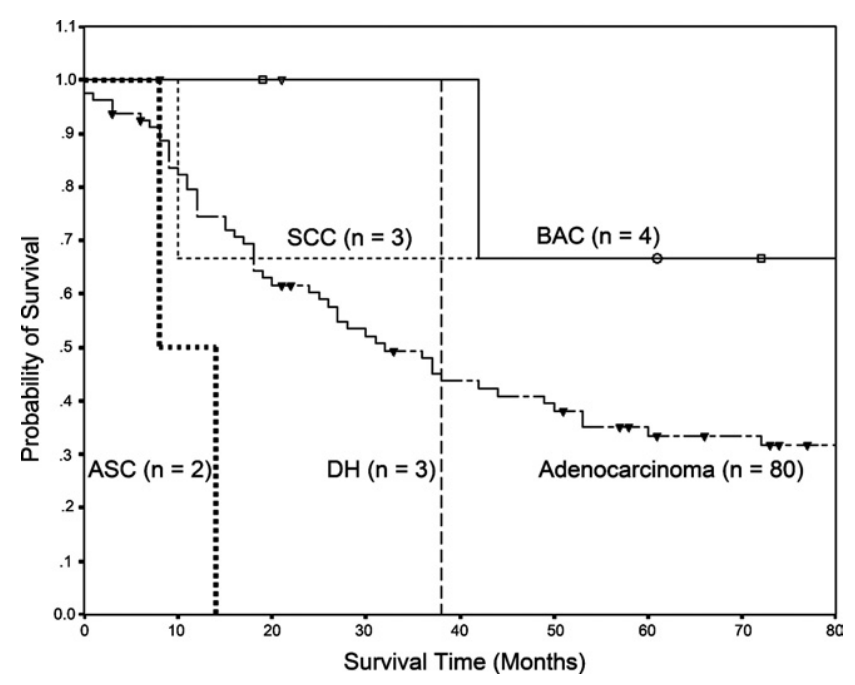

Figure 4. Survival curves of patients with MPLC with bronchioloalveolar carcinoma, adenocarcinoma, squamous cell carcinoma, adenosquamous carcinoma, and different histologic types ( $P=.049$, log-rank test). MPLC, Multiple primary lung cancer; SCC, Squamous cell carcinoma; BAC, bronchioloalveolar carcinoma; $A S C$, adenosquamous carcinoma; $D H$, different histology. 
TABLE 5. Multivariate survival analysis of pathologic features in synchronous multiple primary lung cancers

\begin{tabular}{|c|c|c|c|c|c|}
\hline Variables & No. of patients* & No. of deaths $(\%)$ & Hazards ratio & $95 \% \mathrm{Cl}$ & $P$ value \\
\hline \multicolumn{6}{|l|}{ Histologic type } \\
\hline Bronchioloalveolar carcinoma & 4 & $1(25.0)$ & 0.457 & $0.061-3.407$ & .445 \\
\hline Adenocarcinoma & 80 & $53(66.3)$ & 1.000 & & \\
\hline Squamous cell carcinoma & 3 & $1(33.3)$ & 0.226 & $0.028-1.823$ & .163 \\
\hline Adenosquamous carcinoma & 2 & $2(100.0)$ & 2.782 & $0.594-13.024$ & .194 \\
\hline Different subtypes & 3 & $1(33.3)$ & 1.419 & $0.188-10.706$ & .734 \\
\hline \multicolumn{6}{|l|}{ Vascular invasion } \\
\hline Positive & 17 & $14(82.4)$ & 1.889 & $0.937-3.808$ & .076 \\
\hline Negative & 75 & $44(58.7)$ & 1.000 & & \\
\hline \multicolumn{6}{|l|}{ Lymph node metastasis } \\
\hline Positive & 42 & $35(83.3)$ & 2.367 & $1.196-4.682$ & .013 \\
\hline Negative & 50 & $23(46.0)$ & 1.000 & & \\
\hline \multicolumn{6}{|l|}{ Extranodal extension } \\
\hline Positive & 17 & $15(88.2)$ & 1.172 & $0.560-2.451$ & .674 \\
\hline Negative & 73 & $41(56.2)$ & 1.000 & & \\
\hline
\end{tabular}

$\mathrm{Cl}$, Confidence interval. * Some of the patients lack information.

patients with and without lymph node metastasis, respectively $(P<.001)$.

\section{Discussion}

MPLC is an uncommon entity in comparison with multiple primary cancers in other paired organs such as the ovaries and breasts. ${ }^{8,9}$ Few studies have reported synchronous MPLCs, but among these, the reported incidence was approximately $1 \%$ to $8 \%$ of all lung cancer cases. ${ }^{3,5,10-13}$ In our series, the incidence was $5.6 \%$. The optimal management of patients with MPLCs remains controversial. It is often difficult to determine whether multiple lesions represent multifocal lung cancers or intrapulmonary metastases. The accurate diagnostic method based on genetic analysis of concurrent detection of p53 and epidermal growth factor receptor mutations resolves these issues in our recent report, ${ }^{6}$ in which we described 22 patients with the same clonal tumors and 28 patients with different clonal tumors. Our results showed no statistical association between tumor clonality and patient survival, implying that MPLCs should be resected regardless of their clonal origin. Nevertheless, correlations between lymph node metastasis and intrapulmonary metastatic tumors, from tumors with the same clonality, and poor patient survival support the clinical application of clonality assessment in MPLCs.

All patients with MPLCs in our series were designated as having advanced disease because they were classified with stage IIIB or stage IV NSCLC, according to the current staging nomenclature. ${ }^{7}$ The 5 -year survival of $35.3 \%$ in this study is also similar to that of other reports of $0 \%$ to $69 \%$ for synchronous MPLCs quoted in the literature. ${ }^{10,12,14-18}$ In separate analyses, Okada and colleagues ${ }^{19}$ and Okumura and colleague ${ }^{20}$ found that node-negative patients with intrapulmonary metastases had 5-year survivals of $45 \%$ and $37 \%$, respec- tively. In our large cohort of patients with MPLCs, we found a favorable 5-year survival of 52.5\% among the node-negative patients compared with $15.5 \%$ in node-positive patients. Our analysis confirms that lymph node status is the best predictor of survival among patients who undergo resection for treatment of synchronous MPLCs. It has been suggested that nodal factor would not be ignored in the 1997 staging system.

In addition, we found that extranodal extension of regional lymph nodes and blood vessel invasion are poor prognostic factors among patients with MPLCs, which are similar to the findings of our previous studies of surgically resected NSCLC. ${ }^{21,22}$ In addition, as in the reports mentioned before, the better prognosis among our patients with synchronous squamous cell carcinomas and bronchioloalveolar carcinomas is in keeping with the generally acknowledged more favorable outlook for lung cancers of these subtypes. ${ }^{11,14}$

Several studies ${ }^{2,13,23,24}$ showed that in patients with bilateral synchronous MPLCs, separate and delayed resections are safer and have reasonable surgical mortality and morbidity rates. Furthermore, wedge or segmental resection is thought to increase local recurrence, as reported by some authors. ${ }^{25-27}$ Both of these situations seemed inappropriate to us. In our series, we did not find any difference in long-term results when we compared the group of patients who underwent lobectomy or pneumonectomy with the group of patients who underwent wedge resection or segmentectomy. Our surgical mortality rate of $1.1 \%$ compares favorably with reported perioperative death rates of $4.5 \%$ to $20 \%$ for synchronous MPLCs. ${ }^{5,9,10,23,26,28}$

The operative management of these patients requires careful analysis at each stage of evaluation. A search for extrapulmonary primary cancer is mandatory. The preoper- 
ative pulmonary function test is of utmost importance, because many patients with multiple synchronous lesions require more extensive resection. We believe that formal lung resection should be performed whenever possible, although wedge or segmental resection is an acceptable alterative for patients with resectable disease who are unable to tolerate formal lung resection for treatment of MPLCs. It has been suggested that intraoperative video-assisted thoracoscopic lymphadenectomy of the paratracheal, pretracheal, subaortic, and subcarinal lymph nodes for frozen-section before resection should be routinely performed. Only patients with no evidence of disease after this thorough evaluation proceed to surgical resection.

In contrast with former definitions, the new staging system limits the staging of multiple synchronous tumors to lesions with the same histology and possible metastatic disease. ${ }^{7}$ Synchronous satellite pulmonary nodules situated in the same lobe are considered to be locally advanced disease and are staged as T4 (stage IIIB), whereas tumors located in different lobes are staged as metastatic disease (stage IV). ${ }^{7}$ However, our favorable results suggest that this particular form of NSCLCs would represent a selected population different from patients with widely metastatic disease, and this clearly indicates one of the shortcomings of the conventional staging system.

On the basis of our experience, we could regard MPLCs as local disease rather than systemic disease. This study showed that the presence of lymph node metastasis is an independent adverse prognostic factor in patients with surgically resected synchronous MPLCs. The extranodal extension of regional lymph nodes, tumors with vascular invasion, and tumors with adenosquamous carcinoma or different histologic types also influence patient prognosis. Therefore, we recommend complete surgical resection of unilateral and bilateral synchronous MPLCs in node-negative patients with adequate pulmonary reserve.

We thank Mr Wen-Chen Wu for help with the preparation of the article and artwork.

\section{References}

1. Beyreuther H. Multipicate von carcinomen bei einem fall von sog. Schenecberger Lungenkrebs mit tuberkulose. Virchows Arc. 1924;250: 230-43.

2. Adebonojo SA, Moritz DM, Dandy CA. The results of modern surgical therapy for multiple primary lung cancers. Chest. 1997;112:693701.

3. Battafarano RJ, Meyers BF, Guthrie TJ, Cooper JD, Patterson GA. Surgical resection of multifocal non-small cell lung cancer is associated with prolonged survival. Ann Thorac Surg. 2002;74:988-94.

4. Shimizu S, Yatabe Y, Koshikawa T, Haruki N, Hatooka S, Shinoda M, et al. High frequency of clonally related tumors in cases of multiple synchronous lung cancers as revealed by molecular diagnosis. Clin Cancer Res. 2000;6:3994-9.
5. Martini N, Melamed MR. Multiple primary lung cancers. J Thorac Cardiovasc Surg. 1975;70:606-12.

6. Chang YL, Wu CT, Lin SC, Hsiao CF, Jou TS, Lee YC. Clonality and prognostic implications of p53 and epidermal growth factor receptor somatic aberrations in multiple primary lung cancers. Clin Cancer Res. 2007; 13:52-8.

7. Mountain CF. Revisions in the international system for staging lung cancer. Chest. 1997;111:1710-7.

8. Struve-Christensen E. Diagnosis and treatment of bilateral primary bronchogenic carcinoma. J Thorac Cardiovasc Surg. 1971;61:501-13.

9. Shields TW, Drake CT, Sherrick JC. Bilateral primary bronchogenic carcinoma. J Thorac Cardiovasc Surg. 1964;48:401-13.

10. Deschamps C, Pairolero PC, Trastek VF, Payne WS. Multiple primary lung cancer. J Thorac Cardiovasc Surg. 1990;99:769-78.

11. Carey FA, Donnelly SC, Walker WS, Cameron EWJ, Lamb D. Synchronous primary lung cancers: prevalence in surgical material and clinical implications. Thorax. 1993;48:344-6.

12. Pommier RF, Vetto JT, Lee JT, Johnston KM. Synchronous non-small cell lung cancers. Am J Surg. 1996;171:521-4.

13. Ferguson MK, DeMeester TR, DesLauriers J, Little AG, Piraux M, Golomb H. Diagnosis and management of synchronous lung cancers. J Thorac Cardiovasc Surg. 1985;89:378-85.

14. Roberts PF, Straznicka M, Lara PN, Lau DH, Follette DM, Gandara DR, et al. Resection of multifocal non-small cell lung cancer when the bronchioloalveolar subtype is involved. J Thorac Cardiovasc Surg. 2003; 126:1597-602.

15. Rosengart TK, Martini N, Ghosn P, Burt M. Multiple primary lung carcinomas: prognosis and treatment. Ann Thorac Surg. 1991;52: 773-9.

16. Rea F, Zuin A, Callegaro D, Bortolotti L, Guanella G, Sartori F. Surgical results for multiple primary lung cancers. Eur J Cardiothorac Surg. 2001;20:489-95.

17. van Rens MTM, Zanen P, de la Riviere AB, Elbers HRJ, van Swieten HA, van den Bosch JMM. Survival in synchronous vs single lung cancer. Upstaging better reflects prognosis. Chest. 2000;118:952-8.

18. Tsunezuka Y, Matsumoto I, Tamura M, Oda M, Ohta Y, Shimizu J, et al. The results of therapy for bilateral multiple primary lung cancers: 30 years experience in a single centre. Eur J Surg Oncol. 2004;30: 781-5.

19. Okada M, Tsubota N, Yoshimura M, Miyamoto Y, Nakai R. Evaluation of TMN classification for lung carcinoma with ipsilateral intrapulmonary metastasis. Ann Thorac Surg. 1999;68:326-30.

20. Okumura T, Asamura H, Suzuki K, Kondo H, Tsuchiya R. Intrapulmonary metastasis of non-small cell lung cancer: a prognostic assessment. J Thorac Cardiovasc Surg. 2001;122:24-8.

21. Lee YC, Wu CT, Kuo SW, Tseng YT, Chang YL. Significance of extranodal extension of regional lymph nodes in surgically resected non-small cell lung cancer. Chest. 2007;131:993-9.

22. Wu CT, Chang YL, Shih JY, Lee YC. The significance of estrogen receptor B in 301 surgically treated non-small cell lung cancers. J Thorac Cardiovasc Surg. 2005;130:979-86.

23. Ribet M, Dambron P. Multiple primary lung cancers. Eur J Cardiothorac Surg. 1995;9:231-6.

24. Aziz TM, Saad RA, Glasser J, Jilaihawi AN, Prakash D. The management of second primary lung cancers. A single centre experience in 15 years. Eur J Cardiothorac Surg. 2002;21:527-33.

25. Mathisen DJ, Jensik RJ, Faber P, Kittle CF. Survival following resection for second and third primary lung cancers. $J$ Thorac Cardiovasc Surg. 1984;88:502-10.

26. Jensik RJ, Faber LP, Kittle CF, Meng RL. Survival following resection for second primary bronchogenic carcinoma. $J$ Thorac Cardiovasc Surg. 1981;82:658-68.

27. Shields TW. Multiple primary bronchial carcinomas. Ann Thorac Surg. 1974;27:1-2.

28. Verhagen AF, Tavilla G, van de Wal HJ, Cox AL, Lacquet LK. Multiple primary lung cancers. Thorac Cardiovasc Surg. 1994;42: 40-4. 